\title{
Combinatorial Expression Patterns of LIM-Homeodomain and Other Regulatory Genes Parcellate Developing Thalamus
}

\author{
Yasushi Nakagawa and Dennis D. M. O'Leary \\ Molecular Neurobiology Laboratory, The Salk Institute, La Jolla, California 92037
}

The anatomical and functional organization of dorsal thalamus (dTh) and ventral thalamus (vTh), two major regions of the diencephalon, is characterized by their parcellation into distinct cell groups, or nuclei, that can be histologically defined in postnatal animals. However, because of the complexity of dTh and vTh and difficulties in histologically defining nuclei at early developmental stages, our understanding of the mechanisms that control the parcellation of dTh and vTh and the differentiation of nuclei is limited. We have defined a set of regulatory genes, which include five LIM-homeodomain transcription factors (Is/1,Lhx1,Lhx2, Lhx5, and Lhx9) and three other genes (Gbx2, Ngn2, and Pax6), that are differentially expressed in dTh and vTh of early postnatal mice in distinct but overlapping patterns that mark nuclei or subsets of nuclei. These genes exhibit differential expression patterns in dTh and vTh as early as embryonic day 10.5, when neurogenesis begins; the expres-

The brain and spinal cord are comprised of hundreds of distinct cell groups that constitute layers of laminated structures, such as the cerebral cortex and cerebellum, and nuclei of nonlaminated structures, such as the diencephalon and hindbrain. These organizations are the culmination of progressive developmental processes controlled by regulatory genes. Investigations of the roles of regulatory genes in these processes have focused on early parcellation of the brain into major regions and the later specification of cell types. This study describes regulatory genes that may control the specification and differentiation of the nuclei of dorsal thalamus (dTh) and ventral thalamus (vTh), two regions of the diencephalon.

The $\mathrm{dTh}$ is parcellated into over one dozen nuclei. The principal sensory nuclei, dorsal lateral geniculate (dLG), ventroposterior (VP), and ventral medial geniculate (MGv), relay sensory information from the periphery to primary sensory areas of the neocortex, visual, somatosensory, and auditory, respectively, via thalamocortical axons (TCAs). Other nuclei, such as posterior (Po) and lateral posterior (LP), project broadly to cortex (Jones, 1985, 1998). The vTh has three major nuclei, reticular (RT), zona incerta (ZI), and ventral lateral geniculate (vLG) (Lin et al., 1990;

\footnotetext{
Received Oct. 9, 2000; revised Jan. 10, 2001; accepted Jan. 11, 2001.

This work was supported by National Institutes of Health Grant R01 NS31558. Y.N. has been supported by the Human Frontier Science Program, the Uehara Memorial Foundation, and the Sam Hersch Cerebral Palsy Foundation. We thank D. Anderson, S. Bertuzzi, G. Chapman, L. Jurata, Q. Ma, S. Pfaff, and L. Sommer for cDNAs, M. Goulding, T. Jessell, and S. Pfaff for antibodies, K. Lee, K. Sharma, and J. Thalor for advice on immunostaining, and S. Bertuzzi, G. Lemke, S. Pfaff, R. Tuttle, and D. van Myel for comments on this manuscript.

Correspondence should be addressed to Dennis D. M. O'Leary, Molecular Neurobiology Laboratory, The Salk Institute, 10010 North Torrey Pines Road, La Jolla, CA 92037. E-mail: doleary@salk.edu.

Copyright (C) 2001 Society for Neuroscience $\quad 0270-6474 / 01 / 212711-15 \$ 15.00 / 0$
}

sion of most of them is detected as progenitor cells exit the cell cycle. Soon thereafter, their expression patterns are very similar to those that we observe postnatally, indicating that unique combinations of these genes mark specific cell groups from the time they are generated to their later differentiation into nuclei. Our findings suggest that these genes act in a combinatorial manner to control the specification of nuclei-specific properties of thalamic cells and the differentiation of nuclei within dTh and vTh. These genes may also influence the pathfinding and targeting of thalamocortical axons through both cell-autonomous and non-autonomous mechanisms.

Key words: dorsal thalamus; neuronal specification; thalamic nuclei; thalamocortical projection; transcription factors; LIMhomeodomain; Isl1; Lhx1; Lhx2; Lhx5; Lhx9; Pax6; Gbx2; Ngn2; RPTP8; ventral thalamus

Kolmac and Mitrofanis, 1998). Different domains of embryonic vTh are required for TCA pathfinding (Tuttle et al., 1999).

The vTh and dTh have been defined as adjacent domains of the embryonic diencephalic alar plate based on expression of the homeodomain transcription factors $D l \times 2$ and $G b x 2$, respectively (Bulfone et al., 1993; Puelles and Rubenstein, 1993; Puelles, 1995; Rubenstein et al., 1998), and restrictions in cell movement (Figdor and Stern, 1993). However, little is known about the organization of embryonic dTh and vTh into discrete cell groups that presage their differentiation into nuclei, because the morphology and connections that define nuclei (Jones, 1985) emerge late in development. We have identified regulatory genes expressed in subsets of nuclei postnatally and then used them as markers to analyze the early patterning and progressive parcellation of dTh and vTh.

The LIM-homeodomain (LIM-HD) family of transcription factors, as well as Gbx2, Pax6, and Neurogenin2 (Ngn2), are candidates to be differentially expressed within dTh and vTh and control their parcellation. The LIM-HD genes $L h x 1$ and $L h x 5$ are expressed in early embryonic diencephalon (Fujii et al., 1994; Sheng et al., 1997), Lhx2 and $L h x 9$ in embryonic dTh (Retaux et al., 1999), and Isl1 in adult RT (Thor et al., 1991). LIM-HD genes are intriguing because their unique combinations mark subsets of spinal neurons and specify their phenotypes, including axonal projections (Hobert and Westphal, 2000; Jurata et al., 2000). Gbx2 is expressed broadly early in dTh (Bulfone et al., 1993) and later in a subset of nuclei that require it for their differentiation, as well as for the development of the TCA projection (Miyashita-Lin et al., 1999). Pax6, a paired-box transcription factor, is expressed broadly early in vTh (Walther and Gruss, 1991), later more discretely (Stoykova and Gruss, 1994; Stoykova et al., 1996; 
Kawano et al., 1999), and is required for development of RT, ZI, and vLG (Stoykova et al., 1996; Grindley et al., 1997; Warren and Price, 1997) and TCA pathfinding (Kawano et al., 1999). Ngn2, a basic helix-loop-helix transcription factor expressed in a subset of progenitor cells in dTh (Gradwohl et al., 1996; Sommer et al., 1996), is required for sensory neuron differentiation and dorsoventral patterning of the telencephalon (Fode et al., 1998; Ma et al., 1999; Fode et al., 2000). Here we show that these regulatory genes are expressed in distinct yet often overlapping patterns, suggesting that they cooperate to control the specification and differentiation of thalamic nuclei and cell types.

\section{MATERIALS AND METHODS}

Animals. Embryos and postnatal pups were obtained from timed pregnant ICR mice (Harlan Sprague Dawley, Indianapolis, IN). The day of insemination and birth are designated embryonic day 0.5 (E0.5) and postnatal day $0(\mathrm{P} 0)$, respectively. Embryos younger than E14 were also staged according to external features (Kaufman, 1995).

Anatomical and axial nomenclature. Identification of $\mathrm{dTh}$ and $\mathrm{vTh}$ nuclei at P2 is based on atlases (Paxinos et al., 1994; Franklin and Paxinos, 1997) and patterns of cytochrome oxidase (CO) histochemistry (Figs. 1, 2) (Nicolelis et al., 1995). Retrograde labeling of dTh neurons from different neocortical areas was also used to help identify dTh nuclei (our unpublished data). Histological boundaries between nuclei are not clear at early embryonic stages. Therefore, we have tentatively identified early embryonic cell groups as prospective nuclei by comparing gene expression patterns with those defined at P2 and late embryonic stages.

To facilitate the comparison with other studies, for E12.5 and older brains, we used an axial nomenclature conventionally used for later developmental stages. Sections cut perpendicular to the base of forebrain are referred to as "coronal." On the other hand, at E10.5, coronal sections were cut perpendicular to the true longitudinal axis, with dTh located caudal to vTh, not dorsal to it (Puelles, 1995).

In situ hybridization. In situ hybridization and counterstaining on 20 $\mu \mathrm{m}$ cryosections were performed as described by Tuttle et al. (1999). The following digoxigenin-labeled RNA probes were used: Lhx2 (mouse full-length clone; from L. Jurata, Salk Institute, La Jolla, CA); Lhx9 (mouse full-length clone; from S. Bertuzzi, Salk Institute); Gbx2 (mouse full-length clone; from G. Chapman, University of Adelaide, Adelaide, Australia); Ngn2 (rat full-length clone; from Q. Ma, California Institute of Technology, Pasadena, CA); Lhxl (mouse full-length clone; from S. Pfaff, Salk Institute); $L h \times 5$ (mouse full-length clone; from S. Bertuzzi); Isl1 and Isl2 (rat full-length clones; from S. Pfaff); RPTPS (rat 3' UTR; from D. Anderson, California Institute of Technology); and Pax6 (rat partial clone; obtained by reverse transcription-PCR). Expression patterns of two different genes in adjacent sections were compared by overlaying panels using Photoshop 5.02 (Adobe Systems, San Jose, CA).

Immunostaining. Immunostaining was performed on $20 \mu \mathrm{m}$ cryosections according to Liem et al. (1997). Primary antibodies used included anti-Lhx2/9 (rabbit polyclonal, diluted at 1:4000; from T. Jessell, Columbia University, New York, NY) (Liem et al., 1997), anti-Lhx1/5 (mouse monoclonal, 1:10; clone 4F2 from Developmental Study Hybridoma Bank, University of Iowa, Iowa City, IA; and a rabbit polyclonal, 1:1000; from S. Pfaff) (Tsuchida et al., 1994), anti-Isl1/2 (rabbit polyclonal, 1:4000; from S. Pfaff) (Tsuchida et al., 1994), anti-class III $\beta$-tubulin (TiJ1; mouse monoclonal, 1:500; Babco, Richmond, CA), and antibromodeoxyuridine (BrdU) (rat monoclonal, 1:200; Harlan Sprague Dawley). Because Isl2 is not expressed in either dTh or vTh (data not shown), immunoreactivity with anti-Isl1/2 antibody in dTh or vTh indicates the presence of Isl1 protein. BrdU was injected at $100 \mu \mathrm{g} / \mathrm{gm}$ body weight $1.5 \mathrm{hr}$ before removing embryos. Fluorescence material was analyzed using a confocal microscope (LSM510; Zeiss, Oberkochen, Germany) and Photoshop 5.02.

Cytochrome oxidase histochemistry. $\mathrm{CO}$ histochemistry was performed on fixed, $20 \mu \mathrm{m}$ cryosections as described by Wong-Riley (1979). Sections were incubated overnight at $37^{\circ} \mathrm{C}$ in $0.1 \mathrm{M}$ phosphate buffer containing $5 \%$ sucrose, $0.03 \%$ cytochrome c, $0.02 \%$ catalase, and $0.05 \% \mathrm{DAB}$ and then dehydrated, cleared, and mounted in DPX.

\section{RESULTS}

Most cells in the dTh and vTh of mice become postmitotic between E10.5 and E14.5 (Angevine, 1970). E10.5 is the onset of neurogenesis for cells that form the caudal dTh nuclei, including $\mathrm{dLG}, \mathrm{VP}, \mathrm{LP}, \mathrm{PF}$, and medial geniculate nucleus (MG) (Angevine, 1970; Altman and Bayer, 1989b,c). The generation of neurons that will form the more rostral and medial dTh nuclei begins 1-2 d later (Angevine, 1970). Cells of the three vTh nuclei are generated between E10.5 and E13.5 (Angevine, 1970). Our analysis of gene expression was first done at P2, an age when thalamic nuclei can be readily defined histologically, to determine the relationship of the expression patterns to the nuclei, and then at E16.5, E14.5, E12.5, and E10.5 to cover the period of neurogenesis and the formation of the nuclei. Abbreviations of the anatomical structures used in this study are summarized in Table 1.

\section{Histological organization of dTh and vTh at P2}

At P2, thalamic nuclei can be readily identified based on $\mathrm{CO}$ histochemistry (Figs. 1, 2) and Nissl staining (data not shown). Within dTh, CO histochemistry distinguishes adjacent nuclei based on their different staining levels, such as VP and Po, and dLG and LP, as well as their separation from one another by lightly stained tissue (Fig. $1 A-J$ ). The three major nuclei of vTh, the RT, vLG, and ZI, can also be identified by $\mathrm{CO}$ staining at $\mathrm{P} 2$ (Fig. $2 A-H$ ). The levels of $\mathrm{CO}$ staining vary significantly within vLG, especially at caudal levels (Fig. $2 G, H$ ). ZI is divided into four subdivisions, rostral (ZIr), dorsal (ZId), ventral (ZIv), and caudal, based on locations and CO staining patterns (Nicolelis et al., 1995). Because of the relative proximity to the TCAs, we focused on the rostrally located subdivisions, ZIr, ZId, and ZIv, in the subsequent analyses of gene expression. The border between vLG and ZI is not as evident as other borders (Fig. 2G,H).

\section{Combinatorial expression patterns of LIM-HD and other regulatory genes parcellate postnatal dTh and vTh}

The expression patterns of the selected genes were analyzed at P2 to establish their relationship to thalamic nuclei identified by $\mathrm{CO}$ histochemistry and Nissl staining. We first examined the expression of the closely related LIM-HD genes Lhx2 and Lhx9 (Bertuzzi et al., 1999; Retaux et al., 1999), as well as Gbx2 and Ngn2. Lhx2 is expressed mainly in nonprincipal nuclei, including the anteromedial nucleus (AM), centrolateral nucleus (CL), centromedial nucleus $(\mathrm{CM})$, paraventricular nucleus $(\mathrm{PV})$, peripeduncular nucleus (PP), and ventrolateral nucleus (VL) (Fig. $1 K-$ $M, O)$. Among the principal sensory nuclei, only $\mathrm{MG}$ is positive, particularly the lateral part of MGv. VP and dLG do not express $L h \times 2$ at detectable levels (Fig. $1 L-N$ ). $L h x 9$ is expressed in most dTh nuclei; however, its expression is low in VP and MGv and almost absent in ventromedial nucleus (VM) (Fig. 1P-T). The expression of $G b \times 2$ is distinct from both $L h \times 2$ or $L h \times 9$, although it more closely resembles that of $L h \times 2$. Gbx2 is expressed in $\mathrm{MG}$, AM, CL, CM, mediodorsal nucleus (MD), LP, paratenial nucleus (PT), and PV (Fig. $1 U-W, Y)$, but its expression is not detected in dLG, Po, VL, VM, and VP (Fig. $1 V-X$ ). Within MG, Gbx2 is expressed most highly in MGv, especially in its lateral part (Fig. $1 Y)$. Ngn2 is strongly expressed in VM, laterodorsal nucleus (LD), AV, and weakly in VP, dLG, MGv, CM, and VL (data not shown). Thus, $L h x 2, L h x 9, G b x 2$, and $N g n 2$ are expressed in distinct but overlapping patterns in $\mathrm{dTh}$ at $\mathrm{P} 2$, and their borders of expression often correlate with the borders of dTh nuclei. These results are summarized in Table 2.

$L h \times 2, L h x 9$, and $G b x 2$ are not expressed in vTh (Fig. 1 and data not shown). Instead, the patterned expression of a different set of 


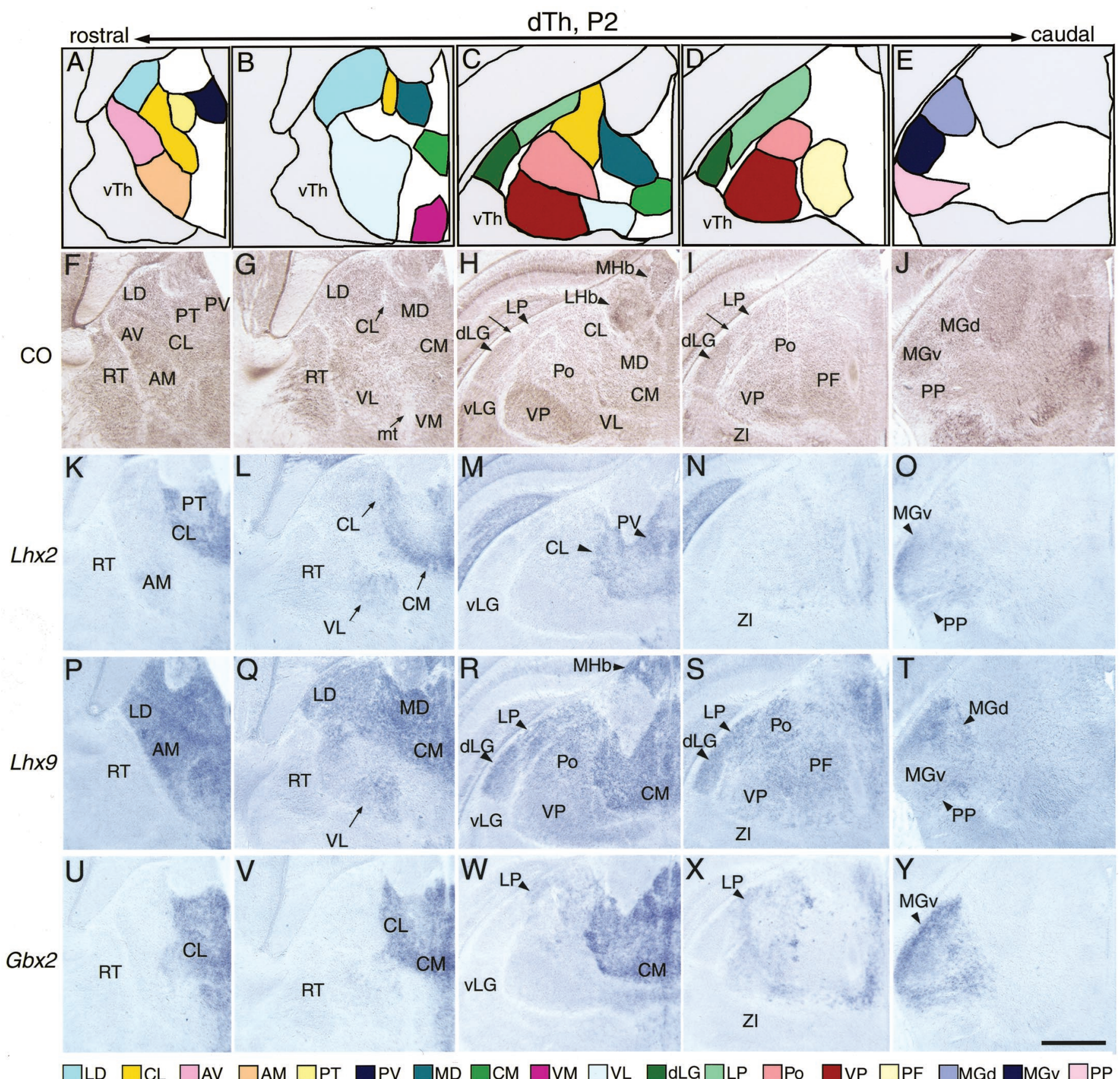

Figure 1. Differential expression of $L h x 2, L h x 9$, and Gbx2 in P2 dorsal thalamus. Coronal sections of diencephalon showing the CO histochemistry $(F-J)$, expression of $L h x 2(K-O), L h x 9(P-T)$, and $G b x 2(U-Y)$ mRNA. In this and all subsequent figures, lateral is to the left and the midline is to the right, and sections to the left are more rostral. Serial sections are aligned in columns in a rostral (top)-to-caudal (bottom) order, unless otherwise noted. $\mathrm{CO}$ staining shows the histological boundaries between dTh nuclei, which are schematized in $A-E$. See Table 1 for abbreviations of anatomical structures. Lhx2 is expressed in AM, CL, CM, PV, PP, and VL. MG also expresses Lhx2, particularly in the lateral part of MGv. VP and dLG do not express $L h x 2$ at detectable levels. $L h x 9$ is expressed in most dTh nuclei; however, its expression is low in VP and MGv and almost absent in VM. Gbx2 is expressed in MG, AM, CL, CM, MD, LP, PT, and PV, but its expression is not detected in dLG, Po, VL, VM, and V P. Within MG, Gbx2 is expressed most highly in MGv, especially in its lateral part. The patterns of differential expression by the three genes are summarized in Table 2. $L H b$, Lateral habenula; $M H b$, medial habenula. Scale bar, $500 \mu \mathrm{m}$.

LIM-HD genes, $L h x 1, L h x 5$, and Isl1, the paired-box gene Pax6, and the receptor tyrosine phosphatase gene $R P T P \delta$ demarcate vTh nuclei at P2. Lhxl is expressed in vLG, as well as ZIr, ZIv, and ZId (Fig. 2I-L). Expression in vLG is not uniform; caudally, it is low in the middle and dorsal parts, in which $\mathrm{CO}$ activity is high (Fig. $2 K, L$ ). $L h x 5$, which is closely related to $L h x l$ (Bertuzzi et al.,
1996), is expressed in vLG, but the level is higher in the dorsal and middle parts, in which Lhxl expression is relatively low (Fig. $2 M-P$ ). $L h x 5$ is expressed at very low levels in ZId and ZIv (Fig. $2 P$ ). Isl 1 is expressed in RT, ZIr, and ZIv (Fig. $2 Q-T$ ), and what appears to be a small domain in the medial part of vLG (Fig. 2R). Pax6 is expressed in a thin strip of cells located in the rostromedial 


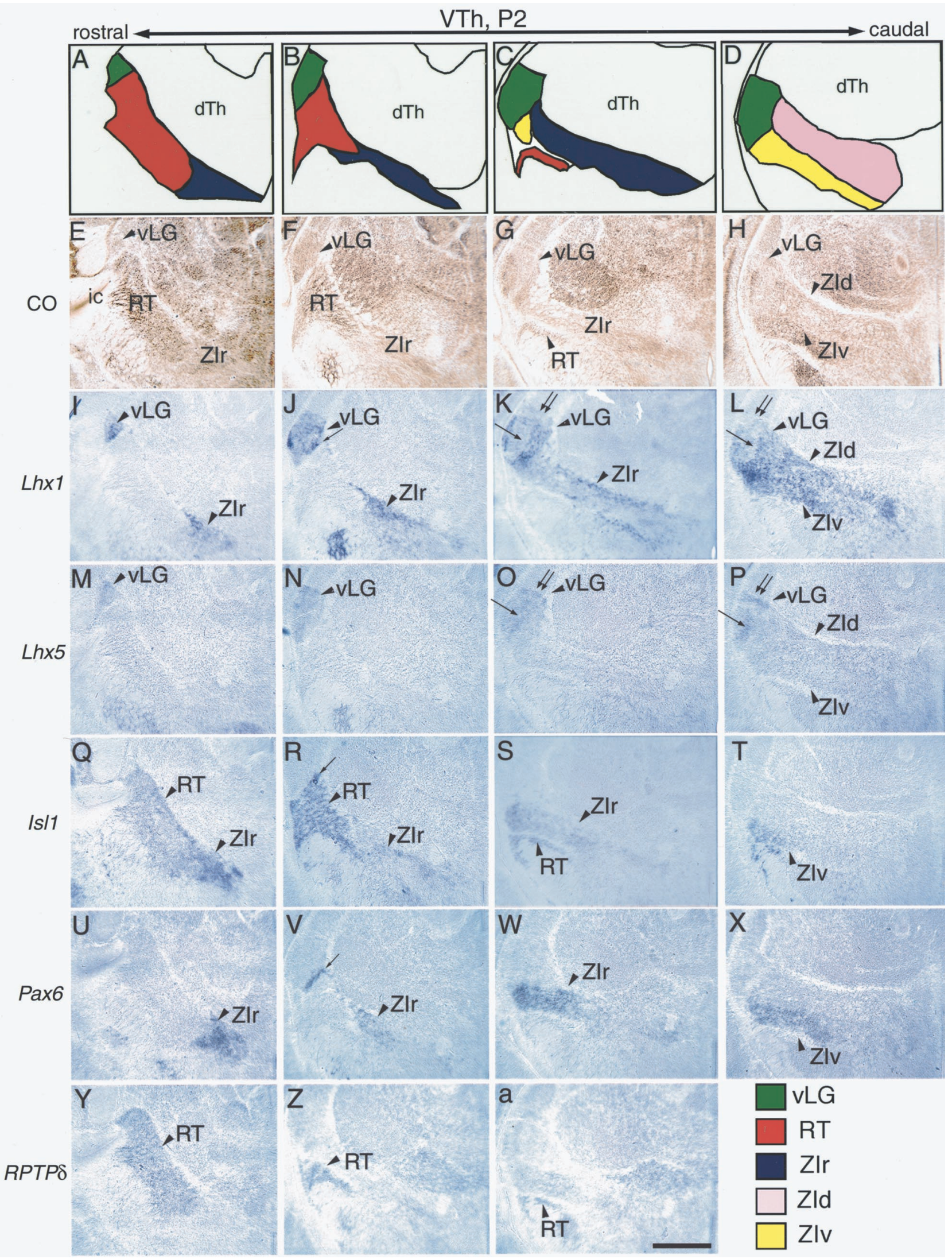

Figure 2. Differential expression of Lhx1, Lhx5, Isl1, Pax6, and RPTPS in P2 mouse ventral thalamus. Coronal sections of mouse diencephalon showing the CO histochemistry $(E-H)$, expression of $\operatorname{Lhxl}(I-L), \operatorname{Lh} x 5(M-P)$, and Isl1 $(Q-T)$, Pax6 $(U-X)$, and $R P T P \delta(Y-a)$ mRNA. Within the same column, serial sections are arranged from rostral-to-caudal in the order of Isl1-Pax6-RPTPS-CO-Lhx1-Lhx5. CO staining shows the histological boundaries between different ventral thalamic nuclei and their subdivisions, which are schematized in $A-D$. Lhx1 is expressed in vLG, (Figure legend continues) 
Table 1. Names and their abbreviations of the anatomical structures used in this study are based on Paxinos et al. (1994) and are listed below

\begin{tabular}{|c|c|}
\hline \multicolumn{2}{|c|}{ Nuclei of dTh (dorsal thalamus) } \\
\hline AM & anteromedial nucleus \\
\hline AV & anteroventral nucleus \\
\hline CL & centrolateral nucleus \\
\hline $\mathrm{CM}$ & centromedial nucleus \\
\hline $\mathrm{dLG}$ & dorsal lateral geniculate nucleus \\
\hline LD & laterodorsal nucleus \\
\hline MD & mediodorsal nucleus \\
\hline MG & medial geniculate nucleus \\
\hline MGv & ventral subdivision of medial geniculate nucleus \\
\hline MGd & dorsal subdivision of medial geniculate nucleus \\
\hline $\mathrm{LP}$ & lateral posterior nucleus \\
\hline PF & parafascicular nucleus \\
\hline Po & posterior complex \\
\hline PP & peripeduncular nucleus \\
\hline $\mathrm{PT}$ & paratenial nucleus \\
\hline PV & paraventricular nucleus \\
\hline VL & ventrolateral nucleus \\
\hline VM & ventromedial nucleus \\
\hline VP & ventroposterior nucleus \\
\hline
\end{tabular}

Nuclei of vTh (ventral thalamus)

\begin{tabular}{ll}
\hline RT & reticular nucleus \\
vLG & ventral lateral geniculate nucleus \\
ZI & zona incerta \\
ZIr & rostral subdivision of zona incerta \\
ZIv & ventral subdivision of zona incerta \\
ZId & dorsal subdivision of zona increta
\end{tabular}

\begin{tabular}{ll}
\hline & Other abbreviations \\
\hline TCAS & thalamocortical axons \\
ic & internal capsule \\
$\mathrm{ZLI}$ & zona limitans intrathalamica \\
$\mathrm{CO}$ & cytochrome oxidase \\
$\mathrm{LHb}$ & lateral habenula \\
$\mathrm{MHb}$ & medial habenula \\
\hline
\end{tabular}

portion of vLG (Fig. $2 \mathrm{~V}$ ), as well as in ZIr and Z Iv but not in RT (Fig. $2 U-X)$. The boundary between RT and Z Ir is also clearly defined by the expression of RPTPS (Mizuno et al., 1993; Sommer et al., 1997; Tuttle et al., 1999), which is expressed in RT but not in ZIr (Fig. 2Y,Z). These results are summarized in Table 3.

In summary, the regulatory genes analyzed here have distinct but overlapping expression patterns in subsets of dTh and vTh nuclei; the expression patterns often correlate with the histologically defined borders of nuclei. In addition, potential subdomains within the same nuclei (e.g., MGv and vLG) are suggested by some of the more discrete expression patterns. Thus, the combinatorial expression of these transcription factors may regulate the postnatal development of dTh and vTh nuclei. Because these genes may also serve as markers to define the organization of the embryonic dTh and vTh into nascent nuclei, or cell groups that will later form these nuclei, we examined their expression at embryonic stages.

\section{Patterned expression of regulatory genes in embryonic dTh}

Although dTh has undergone considerable architectonic differentiation by E16.5, dTh nuclei cannot be as easily distinguished in CO- or Nissl-stained sections as at P2 (data not shown); for example, the dLG borders with LP and MG do not appear as a cell-free band, and the levels of staining are not clearly different

$\leftarrow$

ZIr, ZId, and ZIv. Expression in vLG is not uniform and relatively low in middle and dorsal parts (K, L; arrows and double arrows, respectively). Lhx5 is expressed in vLG and more weakly in ZId and ZIv. Lhx5 expression in vLG is higher in the dorsal and middle parts $(O, P$; arrows and arrowheads, respectively) and is complementary to that of LhxI. Isl1 is expressed in RT, ZIr, and ZIv. It is also possibly expressed in a very small, ventromedial part of vLG $(R ;$ arrow). Pax6 is expressed in a thin band in vLG (V; arrow), ZIr, and ZIv. RPTP $\delta$ is expressed in RT. The patterns of differential expression exhibited by these genes are summarized in Table 3. Scale bar, $500 \mu \mathrm{m}$. 
Table 2. Differential expression of LIM-HD and other transcription factors in P2 mouse dorsal thalamus

\begin{tabular}{lcccc} 
& Lhx2 & Lhx9 & Gbx2 & Ngn2 \\
\hline Principal sensory nuclei & & & & \\
VP & - & +- & - & +- \\
dLG & - & + & - & +- \\
MGv & + & +- & + & +- \\
Other nuclei & & & & \\
AM & +- & + & +- & + \\
AV & - & + & - & + \\
CL & + & + & + & - \\
CM & + & + & + & +- \\
LD & - & + & - & + \\
MD & - & + & + & - \\
MGd & +- & + & + & - \\
LP & - & + & + & - \\
Po & - & + & - & - \\
PP & + & + & - & - \\
PT & - & + & + & - \\
PV & + & + & + & - \\
VL & + & + & - & +- \\
VM & - & - & - & + \\
\hline
\end{tabular}

+, Expressed; +-, weakly expressed; -, not detectable.

Table 3. Differential expression of LIM-HD and other transcription factors in P2 mouse ventral thalamus

\begin{tabular}{lcccc} 
& Lhx1 & Lhx5 & Isl1 & Pax6 \\
\hline vLG & $+{ }^{* a}$ & $+{ }^{* a}$ & $+{ }^{* b}$ & $+{ }^{* b}$ \\
ZI & & & & \\
ZIr & + & +- & + & + \\
ZId & + & +- & - & - \\
ZIv & + & +- & + & + \\
RT & - & - & + & -
\end{tabular}

+ , expressed; +-, weakly expressed; -, not detectable.

${ }^{* a}$ Expression of $L h x 1$ and $L h x 5$ in vLG is nearly complementary.

${ }^{* b}$ Expression of Isl1 and Pax6 is only in small, ventral parts of vLG.

between these nuclei. Nonetheless, it is evident that $\operatorname{Lh} \times 2$, $L h \times 9$, and $G b \times 2$ are differentially expressed in patterns similar to those at P2 (Fig. 3). Robust Lhx2 expression is present in the rostromedial nuclei, i.e., the putative $\mathrm{CL}, \mathrm{CM}$, and $\mathrm{PV}$ (Fig. 3A,B), as well as in MG and PP (Fig. 3C), whereas its expression in dLG and LP is very low and is undetectable in $\mathrm{VP}$ (Fig. $3 B, C$ ). As at $\mathrm{P} 2, \operatorname{Lh} \times 9$ is expressed at high levels in most nuclei except in VM, VP, and MGv (Fig. 3D-F). Gbx2 expression is high in MGv and the dorsal subdivision of medial geniculate nucleus (MGd) and is not detected in VP and dLG (Fig. 3G-I). Although the putative border between LP and dLG is not apparent in CO- or Nissl-stained sections at E16.5, the expression pattern of $G b \times 2$ appears to mark it, with moderate expression in LP and undetectable expression in dLG. The expression pattern of Ngn2 in dTh at E16.5 is similar to that at P2 (Fig. $3 J-L$ ) and is partially complementary to $L h \times 2$ and Gbx2 expression. This suggests that, in dTh, Gbx2/Lhx2 and Ngn2 negatively regulate each others expression, or cells expressing Gbx2/Lhx2 and cells expressing Ngn2 do not mix with each other and thereby remain as distinct cell groups. In summary, the expression patterns of $\operatorname{Lh} \times 2, \operatorname{Lh} \times 9, G b \times 2$, and Ngn2 observed in dTh at P2 are already evident at E16.5,

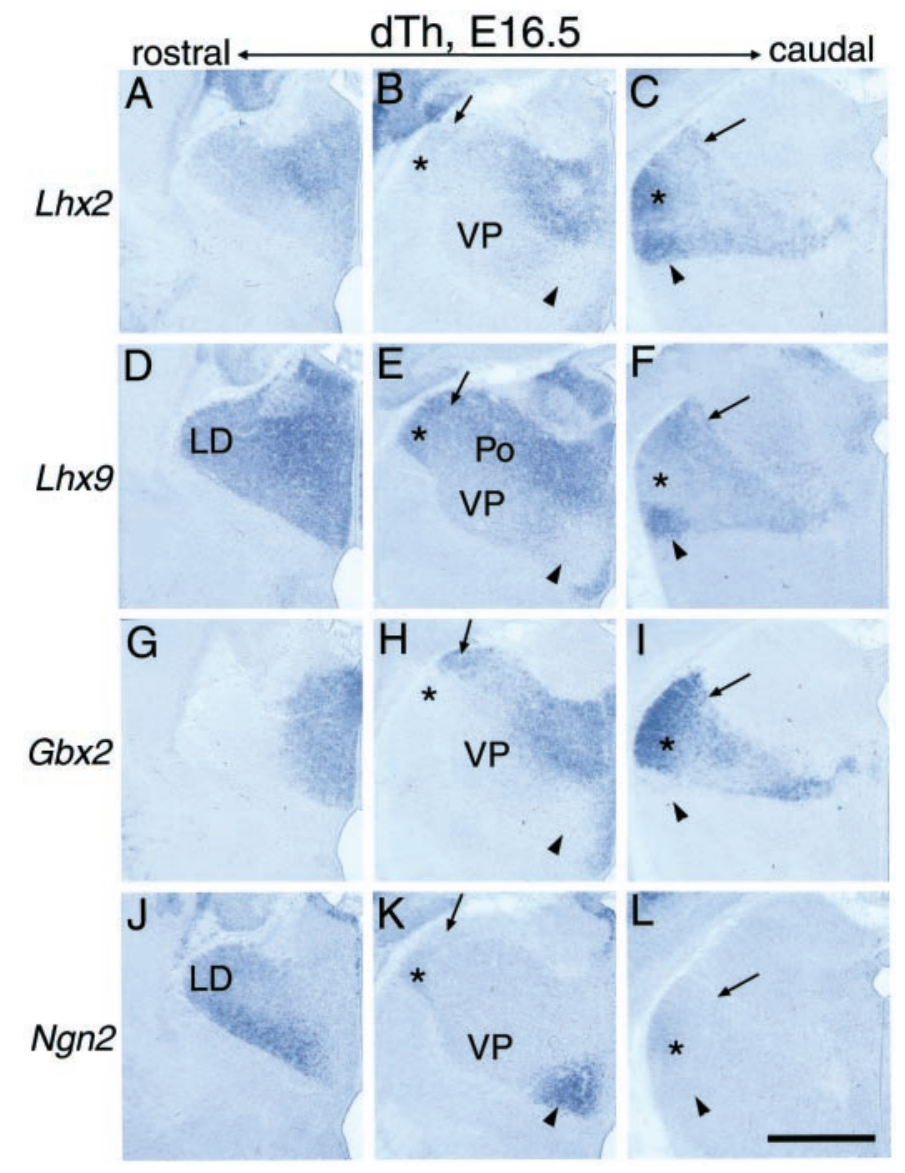

Figure 3. Gene expression patterns in E16.5 mouse dorsal thalamus are similar to those at $\mathrm{P} 2$. Coronal sections of diencephalon showing the expression of Lhx2 $(A-C), L h x 9(D-F), G b x 2(G-I)$, and Ngn2 (J-L) mRNA. At the rostral level, $L h x 9$ is strongly expressed in the putative LD $(D)$, in which $L h x 2$ is only weakly expressed and $G b x 2$ is undetectable ( $A$, $G)$. Ngn2 is expressed in LD $(J)$. At the middle level, the square-shaped region (asterisks) expresses $L h x 9$ and Ngn2 but not $L h x 2$ or Gbx2, compatible with $\mathrm{dLG}(B, E, H, K$; asterisks). The putative LP, located immediately dorsal to dLG, expresses high levels of $L h x 9$ and $G b x 2$ ( $E, H$; arrows) but only very low levels of $L h x 2$ and $N g n 2$ (B, K; arrows). The putative VP is negative for $L h x 2$ and $G b x 2$ and weakly positive for $L h x 9$ and Ngn2. The putative VM is positive for Ngn2 and negative for the others $(B, E, H, K$; arrowheads). At the caudal level, MGv is strongly positive for $L h x 2$ and $G b x 2$ (C, I; asterisks) and weaker for Lhx9 and Ngn2 (F, L; asterisks). The putative PP is positive for $L h x 2$ and $L h x 9$ (C,F; arrowheads) and negative for $G b x 2$ and $N g n 2$ (F, L; arrowheads). MGd expresses $L h x 2$, Lhx 9 , and Gbx2 (E, C, F; arrows) but not Ngn2 (L; arrow). Scale bar, $500 \mu \mathrm{m}$.

suggesting that these genes are useful markers to follow the parcellation of dTh into molecularly distinct cell groups that will form specific dTh nuclei.

It is not possible to histologically distinguish dTh nuclei at E12.5 or E14.5. However, $L h \times 2, L h x 9, G b x 2$, and Ngn2 already show distinct patterns of expression at these ages, and the overall patterns evident at E14.5 are similar to those at E16.5 and P2. For example, caudally, the putative MG already expresses $\operatorname{Lh} x 2, \operatorname{Lh} x 9$, $G b \times 2$, and Ngn2 in a pattern reminiscent of that observed at later ages (Fig. $4 C, F, I, L)$ ). $L h \times 2$ and $G b x 2$ are expressed at high levels in the lateral part of the mantle zone, and Lhx9 and Ngn2 are expressed at low levels in the putative MGv. More rostrally, the putative dLG expresses $L h \times 9$ and $N g n 2$ but not $L h \times 2$ or $G b x 2$ (Fig. $4 B, E, H, K)$. 


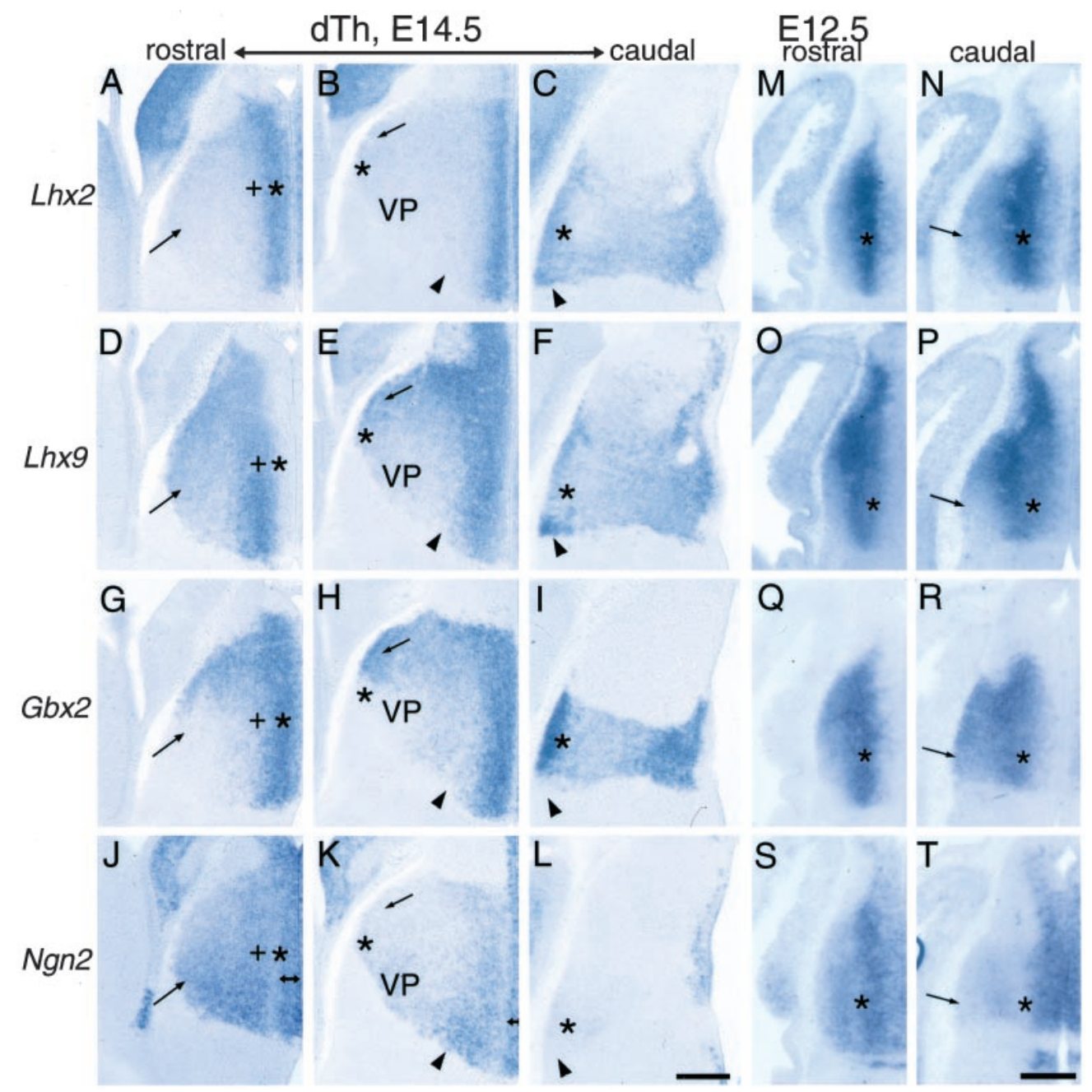

Figure 4. Differential gene expression patterns already exist in the dorsal thalamus at E12.5. Coronal sections of diencephalon showing the expression of $L h x 2(A-C, M, N), L h x 9(D-F, O, P)$, and $G b x 2(G-I, Q, R)$, and $N g n 2(J-L, S, T)$ mRNA. $A-L$ are for E14.5, and $M-T$ are for E12.5. At E14.5, Lhx9 and Ngn2 are expressed in the lateral-ventral part of dTh at the rostral level, corresponding to LD, but Lhx2 and Gbx2 are not (A,D, G, J; arrows). A band of strong $L h \times 2$ and $G b x 2$ expression $(A, G$, asterisks) is located more medially to a band of strong $L h x 9$ expression $(D ;$ cross $)$. Ngn 2 is weak in the band of $L h \times 2$ and $G b x 2$ expression ( $J$; asterisk) but strong in the putative ventricular zone ( $J, K$; double-headed arrow), in which $L h x 2$, Lhx9, and Gbx2 are negative. More caudally, a region expresses $L h x 9$ and Ngn2 but not $L h x 2$ or Gbx2, which is likely to be dLG (B,E,H,K;asterisks). The putative LP, located dorsally to dLG $(B, E, H, K$; arrows), expresses high levels of $\operatorname{Lh} x 9$ and $G b x 2$ but only low levels of $\operatorname{Lh} x 2$ and $N g n 2$. The putative VP is negative for $L h x 2$ and $G b x 2$ and weakly positive for $L h x 9$ and $N g n 2(B, E, H, K)$. The putative PP is positive for $L h x 2$ and $L h x 9$ and negative for $G b x 2$ and $N g n 2$ $(C, F, I, L$; arrowheads), whereas MGv strongly expresses $L h x 2$ and $G b x 2$ and weakly expresses $L h x 9$ and Ngn2 (C,F, I, L; asterisks). These patterns of differential expression are not still apparent at E12.5, but the band with high levels of $L h x 2 / G b x 2$ expression is already located medial to the band with the high $L h x 9$ expression ( $L, N-R$; asterisks), similar to E14.5. Ngn2 is expressed in the ventricular zone, as well as the mantle zone, but is weak in the band with strong $L h \times 2 / G b x 2$ expression $(S, T$; asterisk). Scale bars, $200 \mu \mathrm{m}$.

Although the similarities in gene expression patterns at early and late stages are striking, some differences are also apparent. At E16.5, the expression domains of $L h \times 2$ overlap with those of $L h x 9$ except for MGv, in which $L h x 2$ is highly expressed but Lhx 9 expression is low. However, at E14.5, a rostromedial part of dTh exhibits a high level of Lhx2 expression but a very low level of $L h x 9$ expression (Fig. 4A,D), which is not found at E16.5. This band of cells is located just outside of the ventricular zone and expresses $G b x 2$ at a high level and Ngn2 at a very low level (Fig. $4 G, J$ ). An approximately similar pattern is already apparent at E12.5 (Fig. 4M-T). Another example of a difference in the patterns of gene expression is found between E12.5 and E14.5 in the putative dLG; the overall pattern characteristic of dLG after E14.5 is not evident at the putative location of this nucleus in the caudolateral portion of dTh (Fig. $4 N-T)$.

The band of Gbx2-expressing cells located just outside of the ventricular zone (Fig. 4G,Q, asterisks) has been described to be in the thalamic subventricular zone (Bulfone et al., 1993; Miyashita-Lin et al., 1999). Lhx2 is expressed in a similar band. However, pulse labeling with BrdU $\sim 1 \mathrm{hr}$ before fixation shows that this expression domain of Gbx2 and $L h \times 2$ is BrdUnegative at these ages (data not shown; also see below and Fig. 8), suggesting that this domain is not a proliferative zone and that these cells are postmitotic. A similar study in rat using tritiated thymidine reported the labeling of a few scattered cells in this domain just lateral to the ventricular zone, leading the authors to term this zone the subependymal layer, but noted that a large 


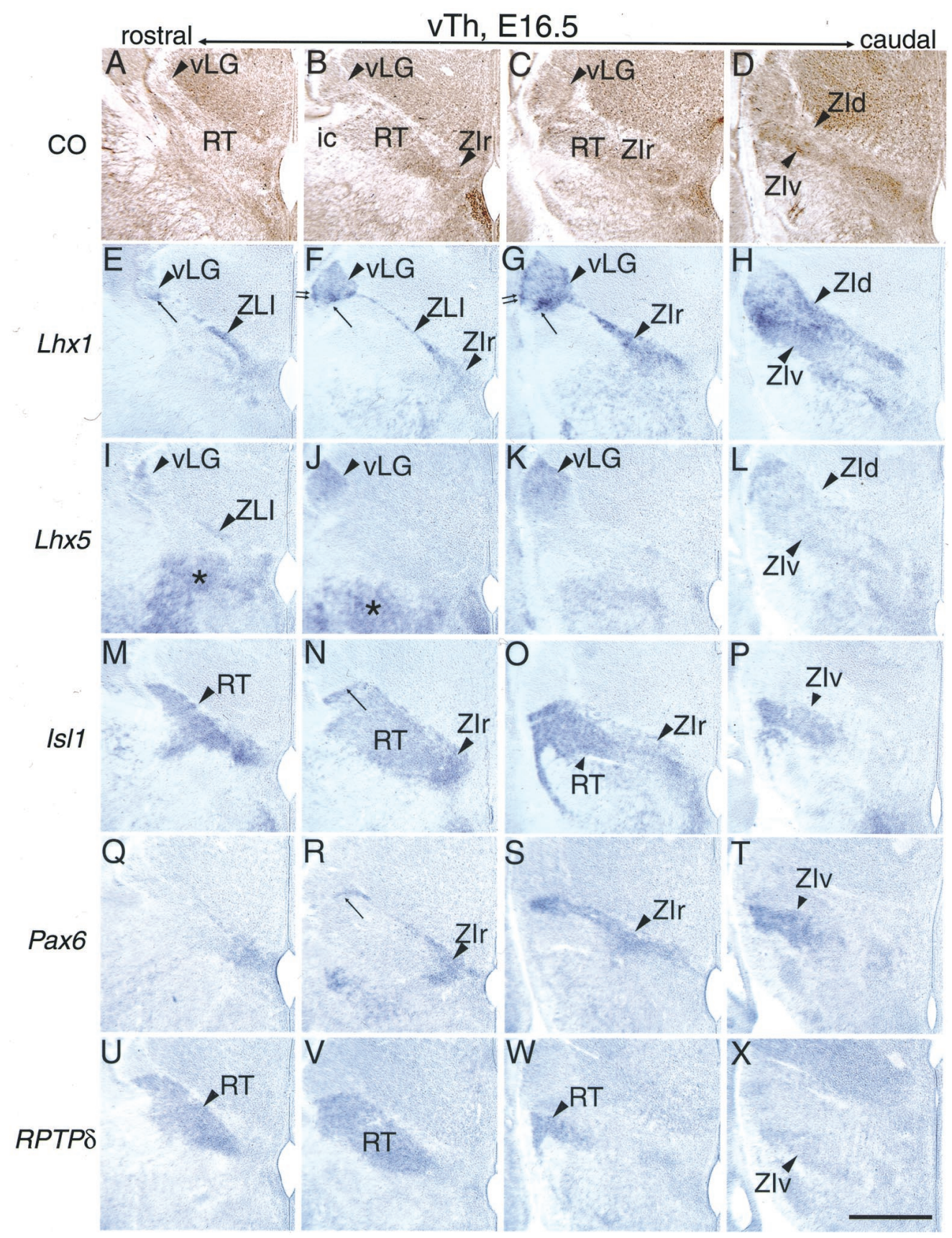

Figure 5. Gene expression patterns in E16.5 mouse ventral thalamus are similar to those at P2. Coronal sections of diencephalon showing the CO

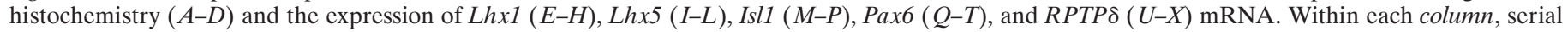
sections are aligned in a rostral-to-caudal order from $L h x 1$ to $R P T P \delta$ and then CO. CO staining shows similar patterns to P2 and delineates the nuclei of vTh $(A-D)$. Lhxl is expressed in vLG, ZIr, ZId, and ZIv. Expression in vLG is high in the ventromedial $(E-G$; arrows) and ventrolateral $(F, G ;$ double arrows) parts. In addition, $L h x 1$ is expressed in ZLI $(E, F)$. Lhx5 is expressed in vLG, most highly in the dorsal part $(I-L)$, and in the most rostral part of ZLI $(I)$. It is also weakly expressed in ZId and ZIv $(L)$. Part of hypothalamus is positive for Lhx5 (I, J; asterisk). Isl1 is expressed in RT, ZIr, ZIv $(M-P)$, and possibly in a small, rostroventral part of vLG $(N$; arrow). Pax6 is expressed in ZIr, ZIv $(S$, T), and a rostroventral part of vLG $(R ;$ arrow $)$. $R P T P \delta$ is expressed in RT and ZIv. Scale bar, $500 \mu \mathrm{m}$.

proportion of the cells in this layer must be postmitotic (Altman and Bayer, 1989a).

In summary, the differential expression patterns of genes that mark dTh nuclei at later ages are already evident in dTh as early as E12.5. These patterns undergo some changes until E16.5, but then the patterns appear to be stable to P2. It is unclear whether changes in these expression patterns between E12.5 and E16.5 are attributable to changes in expression per se or whether the ex- pressing population is the same but the patterns change as a result of cell movements (see Discussion).

\section{Patterned expression of regulatory genes in embryonic vTh}

At E16.5, CO histochemistry suggests that the organization of vTh is similar to that at P2 (Fig. $5 A-D$ ). RT is identified as a sheet of cells interposed between dTh, vLG, ZIr, and the internal capsule 
(ic), and the subdivisions of ZI are evident by their positions and patterns of CO staining. The expression patterns of Lhx1, Lhx5, Isl1, Pax6, and RPTPS in vTh at E16.5 are also similar to P2 (Fig. $5 E-X)$. The only difference observed is that, at E16.5, a thin band of cells expressing Lhxl (Fig. 5E-G), Lhx5 (Fig. 5I), and Pax6 (Fig. $5 R$ ) delineates the dTh-vTh border and extends laterally to vLG. Isll expression also appears to overlap with this band (Fig. $5 N$ ). The location of this band of cells is consistent with its identification as the zona limitans intrathalamica (ZLI), which has been defined in earlier embryos as abutting dTh and vTh and expressing Shh (Sonic hedgehog) (Shimamura et al., 1995).

Patterns of gene expression reveals several distinct cell groups within ZLI; rostrally, it expresses both $L h x 1$ and $L h x 5$ (Fig. 5E,I), whereas caudally, $L h x 1$ is expressed but $L h x 5$ is not $($ Fig. $5 F, J)$. In addition, overlaying Figure 5, $F$ and $R$, as well as doubleimmunostaining shows that the population of ZLI cells expressing Lhxl and those expressing Pax6 are distinct; the former is located immediately dorsal to the latter (data not shown). Therefore, at least three different populations of cells exist in ZLI; one expresses both Lhx1 and Lhx5 but not Pax6, one expresses Lhx1 but not Lhx5 or Pax6, and the third one expresses Pax6 but not Lhx1 or $L h \times 5$. We find that vLG also exhibits heterogeneity in gene expression patterns. As at P2, at E16.5, the expression of Lhxl and Lhx5 is partially complementary. Expression of Pax6 and Lhxl is also exclusive to each other in the ventromedial part of vLG in both in situ hybridization (Fig. $5 F, R$ ) and immunostaining (data not shown). The expression of Lhx5 in dorsal parts of both the ZLI and vLG closely resembles that of $N k \times 2.2$ (data not shown). Based on the relative locations of ZLI and vLG and the disappearance of the ZLI by P2, we assume that the ZLI constitutes migratory streams for cells that eventually form vLG. A similar assumption has been made by Kitamura et al. (1997), in which they suggested that Brxland Nkx2.2 mark dorsal ZLI and vLG, whereas Dlxland Arx mark ventral ZLI and vLG.

At E14.5, nuclei in vTh cannot be distinguished by Nissl or CO staining (data not shown). However, the positional relationships between the gene expression domains of Lhx1, Lhx5, Isl1, Pax6, and $R P T P \delta$ appear to be similar to E16.5 (Fig. 6). Two separate bands of ZLI can be clearly distinguished; the dorsal one extends laterally to the dorsal part of vLG and expresses $L h \times 5$ as well as Lhx1 (Fig. 6A,B,E,F). The ventral one extends laterally to the ventral vLG and expresses $L h x 1$ and Pax6 (Fig. 6A,B,M,N), although cells expressing $L h x l$ and Pax6 rarely overlap (data not shown). The dorsal part of the Isl1-expressing domain also appears to overlap with the ventral band (Fig. $6 J$ ). These results suggest that the cell types of vLG are already specified as they initiate their migration from the ventricular zone.

At E12.5, the differential expression patterns of $L h x 1, L h x 5$, Isl1, and Pax6 appear to be approximately similar to those at E14.5 and later (Fig. 7). The ZLI expresses Lhx1, Lhx5, and Pax6 and extends laterally to the putative vLG; the dorsal part of vLG is characterized by a high level of $L h x 5$ and low level of $L h x 1$ expression (Fig. $7 B, E$ ), whereas the ventral part expresses $L h x l$ (Fig. $7 B$ ). More ventrally, a domain expressing Isl1 but not Lhx1, Lhx5, or Pax6 is located just medial to the bundle of TCAs forming the internal capsule (Fig. $7 B, E, H, J)$. Based on the position of this domain and its pattern of gene expression, which is only found in RT at E14.5 and later, this domain is likely the nascent RT. Between the putative vLG and RT, another domain expressing Lhxl, Isl1, and Pax6 exists and is likely the nascent ZIr or ZIv based on the pattern of gene expression and its relative position (Fig. $7 B, H, J$ ). Positioned more caudally are four distinct domains with gene expression patterns that match those of dorsal vLG, ventral vLG, ZId, and ZIv/ZIr (moving from dorsal to ventral) (Fig. $7 C, F, I, K)$.

Results of immunostaining confirm the above assignments and directly show the molecular heterogeneity of cells within the same nucleus (Fig. $7 L-P$ ); in the putative $\mathrm{ZIr} / \mathrm{ZIv}$, cells that express Isl1 and Lhx1/5 exhibit virtually no overlap rostrally (Fig. 7M) but considerable overlap caudally (Fig. $7 N$ ), whereas those that express Isl1 and Pax6 overlap rostrally and caudally (Fig. 7O,P). Similar patterns are also observed at E14.5 (data not shown), suggesting that the differential expression of these genes not only parcellates and specifies the vTh at the level of presumptive nuclei but is also likely involved in specification of distinct cell types within these nuclei.

\section{Relationship between expression domains and the TCA path}

TCAs extend ventrally from dTh into vTh and, at approximately E12.5, make a sharp lateral-rostral turn at the vTh-telencephalic border and enter ventral telencephalon (Braisted et al., 1999; Tuttle et al., 1999). The turning TCA bundle is identified as a cell-sparse area in $4^{\prime}, 6^{\prime}$-diaminino-2-phenylindole (DAPI) staining (Fig. $7 A^{\prime}, D^{\prime}, G^{\prime}$ ). This bundle is surrounded dorsally and laterally by cell domains expressing $L h x 5$ and both $L h x 1$ and $L h x 5$, respectively (Fig. $7 A, D)$. These cells are likely to be in ventral telencephalon. The Isll-expressing cell domain interpreted to be a rostral extension of the putative RT occupies the dorsomedial part of the TCA bundle (Fig. $7 G, H$ ). The lack of overlap between Isll- and Lhxl/5-expressing cells is confirmed by immunostaining (Fig. $7 L$ ). Lhx1/5-expressing, hypothalamic domain is located medial to the Isl1-expressing RT (Fig. $7 L$ ). Thus, the path taken by the TCA bundle near the diencephalic-telencephalic border is outlined by cell groups that express distinct combinations of LIM-HD genes, suggesting that these genes may differentially regulate the expression of guidance molecules that control TCA pathfinding.

\section{Onset of differential gene expression in dTh and vTh}

To determine whether the regulatory genes analyzed here exhibit patterned expression at the onset of neurogenesis in thalamus, we analyzed their expression at E10.5 when the first thalamic neurons are generated. At this stage, $\operatorname{Lh} x 2, \operatorname{Lh} \times 9$, and $G b \times 2$ are expressed in thin overlapping bands that extend dorsoventrally along the lateral edge of dTh (Fig. $8 A-C$ ). Some expressing cells are scattered in the ventricular zone. In contrast to later ages, Ngn2 is expressed only in the ventricular zone at E10.5 (Fig. 8D). Lhx9 shows a longer expression domain than Lhx2 and Gbx2. Doublelabeling with Lhx2/9 antibodies and BrdU (injected $1.5 \mathrm{hr}$ before fixation) shows that virtually all of the Lhx2/9-positive cells are BrdU-negative, suggesting that they are postmitotic (Fig. $8 E$ ); only a small number of cells near the lateral border of BrdU-positive region are double-labeled with both antibodies. Lhx2/9-positive cells scattered in the ventricular zone are all BrdU-negative. Double-labeling with an Lhx2/9 antibody and antibodies against class III $\beta$-tubulin and microtubule-associated protein- 2 shows that a subpopulation of Lhx2/9-positive cells express these neuronal markers (data not shown). These findings suggest that $L h \times 2$ and/or Lh $x 9$ begin to be expressed around the time the first dTh neurons become postmitotic, and the onset of expression precedes the appearance of neuronal markers.

In the vTh, Lhx1, Lhx5, Isl1, and Pax6 are all expressed at E10.5. LhxI and Isll are expressed in a thin band of cells in the mantle zone (Fig. $8 F, H$ ). In contrast, $L h x 5$ and Pax6 are highly expressed throughout both the mantle and ventricular zones (Fig. 8G,I). The 


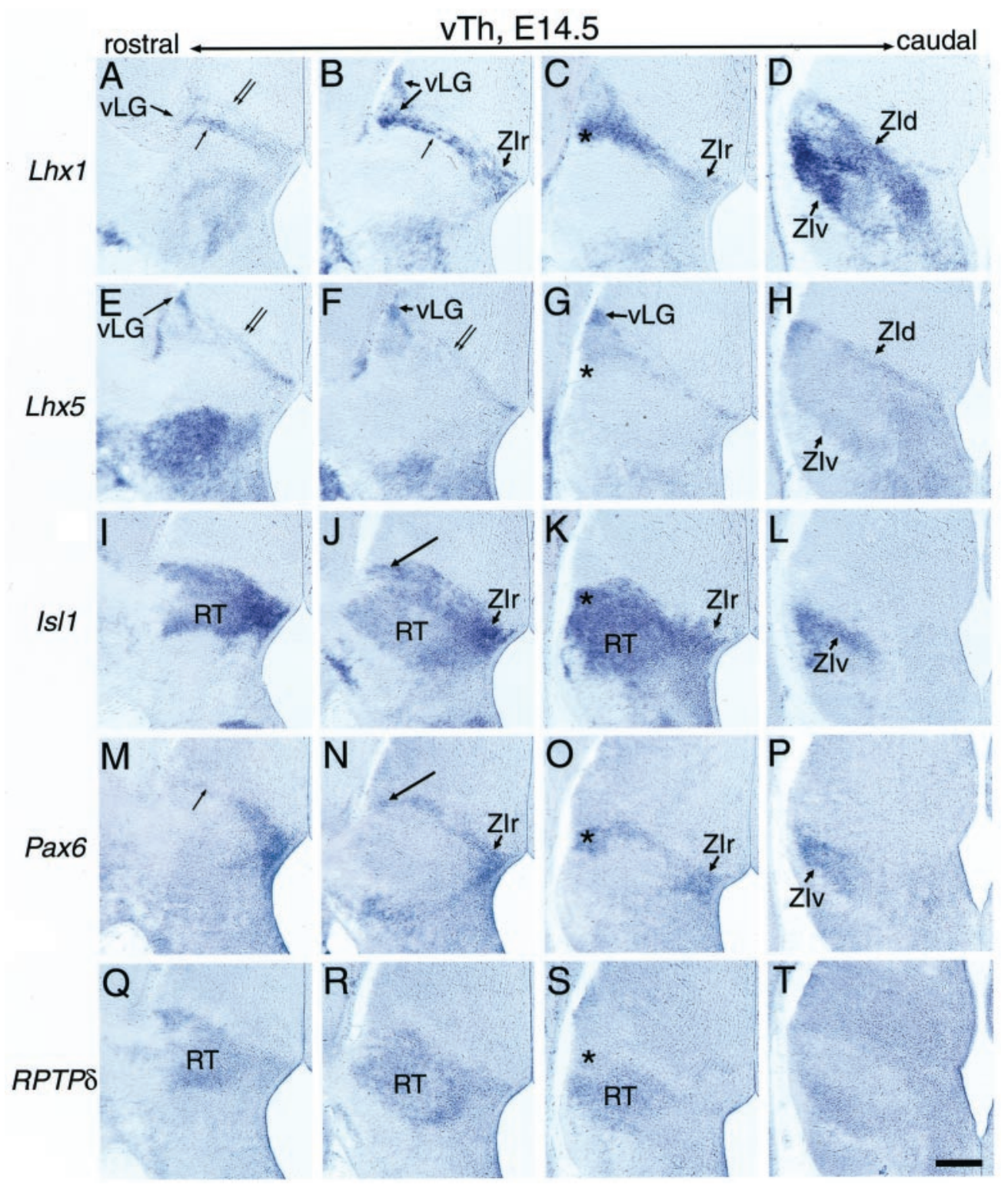

Figure 6. Differential gene expression patterns in E14.5 mouse ventral thalamus is similar to those at E16.5 and P2. Coronal sections of the mouse

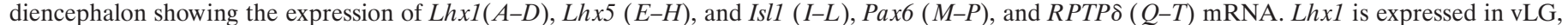
ZIr, ZId, and ZIv. Expression in vLG is high ventrally $(A, B)$. Lhx1 is also expressed in two bands of ZLI (A, B; arrows and double arrows). Lhx5 is expressed in dorsal vLG, as well as the dorsal band of ZLI ( $E, F$; double arrows). Isl1 is expressed in RT, ZIr, and ZIv. Its expression domain appears to extend dorsally to the ventral part of vLG (J; arrow). Pax6 is expressed in ZLI (M, arrow), part of vLG ( $N$; arrow), ZIr, and ZIv. RPTP $\delta$ is expressed in RT and ZIv. Asterisks in $C, G, K, O$, and $S$ appear to be the lateral part of ZIr or ZIv. Scale bar, $200 \mu \mathrm{m}$.

great majority of cells in the ventricular zone that are immunopositive for Lhx5 or Pax6 are also BrdU-positive (data not shown). The expression of these two genes does not become restricted to the mantle zone until E12.5. In contrast, only a few cells in the ventricular zone immunostain for Isl1, and only a small subset of these cells are BrdU-positive (Fig. $8 L$ ). Immunostaining also shows that as early as E10.5, the heterogeneity in vLG cells expressing Lhx1/5, Isl1, and Pax6 observed at later ages is evident in the mantle zone (Fig. $8 J, K$ ).

In summary, the LIM-HD genes $L h x 1, L h \times 2, L h \times 9$, and Isl1, as well as the homeodomain gene $G b x 2$, are expressed by postmitotic cells in the mantle zone of dTh and vTh as it first begins to form. Lhx5 and Pax6 are expressed in postmitotic as well as progenitor cells in the ventricular zone, suggesting that these genes may define specific vTh cell types even at the progenitor cell stage.

\section{DISCUSSION}

\section{Parcellation of dTh and vTh into nuclei}

At P2, when thalamic nuclei are readily distinguished, the regulatory genes studied here are expressed in unique, overlapping patterns that mark specific nuclei or subsets of nuclei. An important issue for assessing the roles of these genes is whether they mark the same cells at earlier times. The expression patterns observed at P2 are also evident at E16.5, when thalamic nuclei are still differentiating but can be defined histologically. Although at E14.5 the borders between prospective thalamic nuclei are often not histologically distinguishable, the locations of the nuclei can be readily approximated, and the expression patterns resemble those at E16.5 and P2. It is more difficult to make this assessment at earlier ages. E12.5 is during thalamic neurogenesis, but a majority of neurons have been gener- 


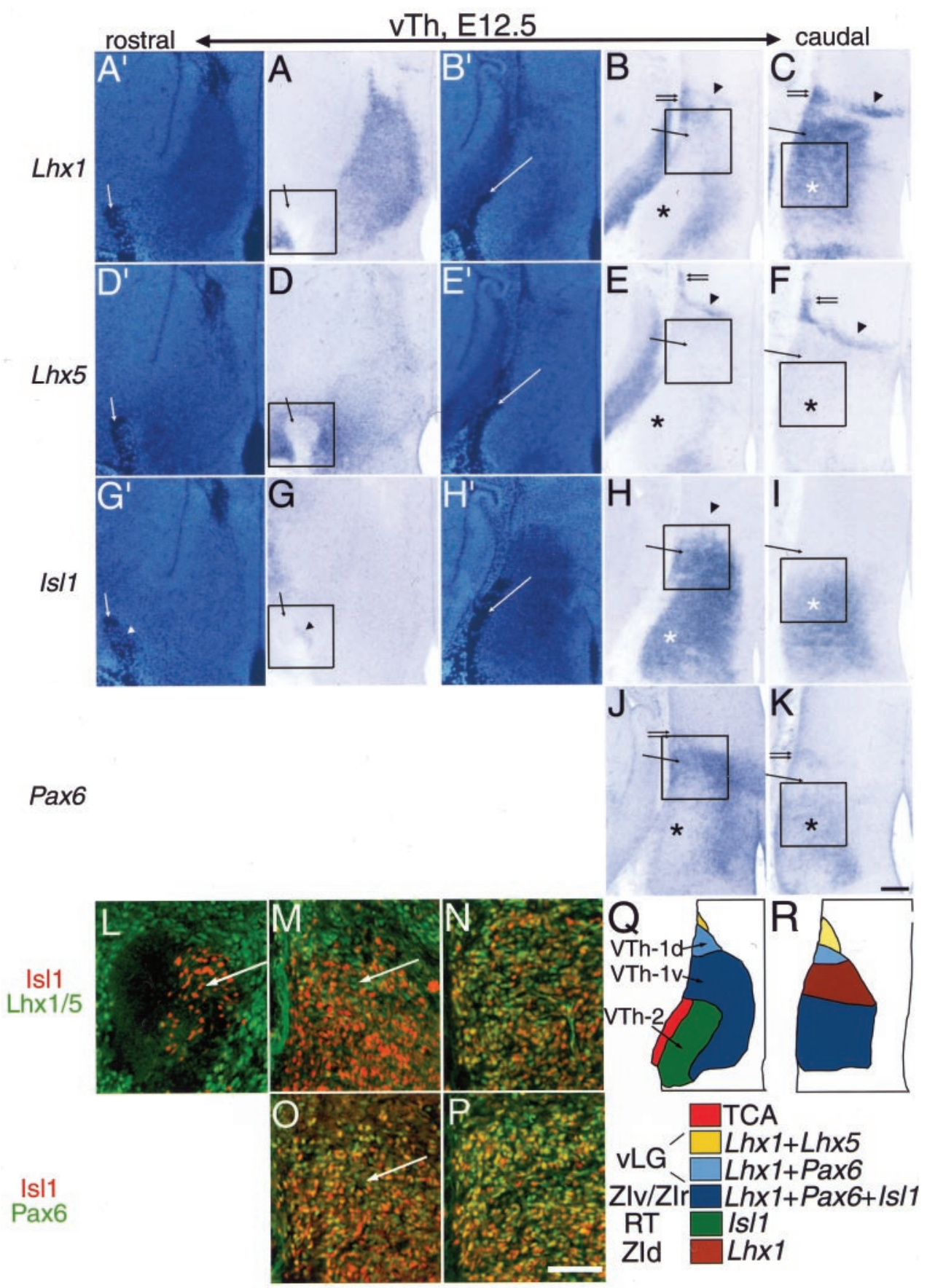

Figure 7. The differential expression of $L h x 1, L h x 5$, Isl1, and Pax6 in the E12.5 ventral thalamus and the region surrounding the tuning TCAs. Coronal sections of the mouse diencephalon showing the expression of $\operatorname{Lhx} 1(A-C), L h x 5(D-F)$, Isl $(G-I)$, and Pax6 $(J, K)$ mRNA and Lhx1/5 ( $L-N)$, Pax6 $(O, P)$, and Isl1 $(L-P)$ protein. $A^{\prime}, B^{\prime}, D^{\prime}, E^{\prime}, G^{\prime}$, and $H^{\prime}$ are the DAPI counterstaining of $A, B, D, E, G$, and $H$, respectively. Note the dark parts in the DAPI staining, which come from the signal of in situ hybridization. $L$ is approximately at the same level as $A, D, a$ nd $\mathrm{G}$, whereas $M / O$ and $N / P$ are at similar levels to $B / E / H / J$ and $C / F / I / K$, respectively. The level of $A / D / G$ is at the level at which TCAs make a lateral turn at the diencephalic-telencephalic border. The TCA bundle is seen as a cell-sparse area $\left(A, A^{\prime}, D, D^{\prime}, G, G^{\prime}\right.$; arrow). This bundle is surrounded by the domain expressing $L h x 1$ and $L h \times 5$ on its lateral, dorsal $(A, D)$, and rostral (data not shown) aspects. The medioventral part of the TCA bundle contains cells expressing Isl $(G$; arrowhead). This domain does not express Lhx1 or Lhx 5 $\left(L ;\right.$ arrow) and continues caudally to the putative RT $\left(H\right.$; asterisk). At the more caudal level $(B, E, H, J, M, O, Q)$, the TCA is on the lateral surface of vTh $\left(B^{\prime}\right.$, $E^{\prime}, H^{\prime}$; arrows), and the putative RT is located immediately medial to it, which express Isll but not Lhx1, Lhx5, or Pax6 (B, E, H, J; asterisks). Just dorsal to RT, there is a domain that expresses Lhxl, Isl1, and Pax6 but not Lhx5 (B,E,H,J; arrows), which is compatible with ZIr or ZIv. Immunostaining of the boxed areas in $B / E / H / J$ shows that in this domain Isl1-expressing cells rarely overlap with Lhx1/5-expressing cells, but they do with Pax6-expressing cells ( $M, O$; arrows). More dorsally, ZLI expresses Lhx1 and Lhx5 but not Isl1 (B, E, H; arrowheads). The putative vLG expresses Lhx1, Lhx5, and Pax6 (B, E, J; double arrows). Expression is high dorsally for $L h x 5$ and ventrally for $L h x 1$ and Pax6. These results are summarized in $O$. The nomenclatures VTh-1d,VTh-1v, and $V T h-2$ were used in our previous study based on the expression of Pax6 and RPTP $\delta$ at E13.5 (Tuttle et al., 1999). At the most caudal level, vLG is again evident as a domain expressing $L h x 1, L h x 5$, and Pax6 (C,F, K; double arrows), as is ZLI (C,F; arrowheads). More ventrally, a domain with high level of $L h x 1$ and low Lhx5 expression but no Isl1 or Pax6 expression is detected, which corresponds to ZId (arrows). The putative ZIv is ventral to ZId and expresses high levels of $L h x 1$, Isll, and Pax6 and very low levels of $L h \times 5$ (asterisks). Immunostaining of the boxed areas in $C / F / I / K$ shows that the ZIv contains heterogeneous populations of cells for expression of Isl1, Lhx1/5, and Pax6 $(N, P)$. These results are summarized in $R$. Scale bar, $50 \mu \mathrm{m}$. 

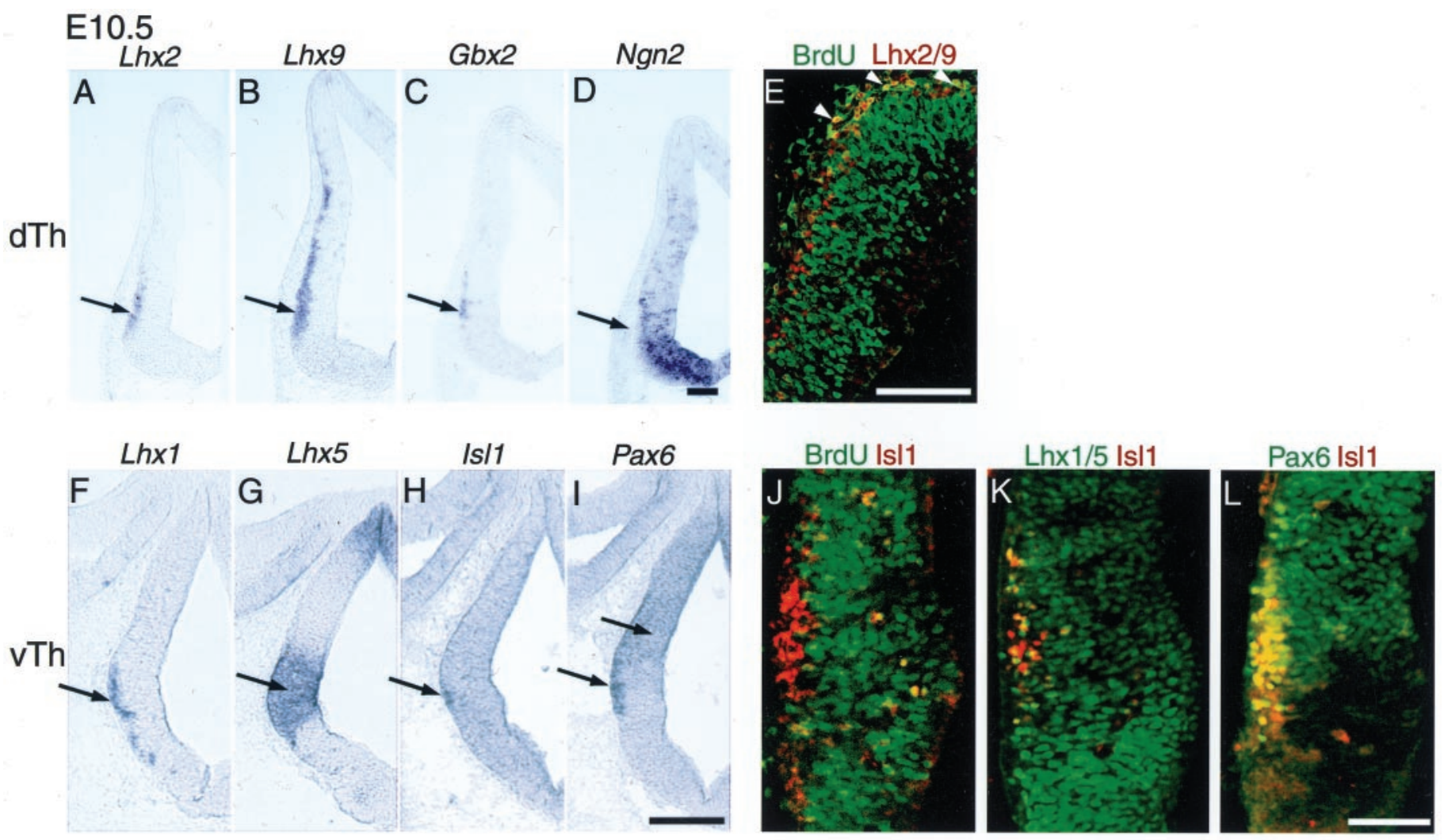

Figure 8. Expression of $\operatorname{Lh} x 2, \operatorname{Lh} x 9, \mathrm{Gbx2}$, and $\mathrm{Ngn} 2 \mathrm{in} \mathrm{dTh}$ and $\operatorname{Lh} x 1, \operatorname{Lh} x 5$, Isl1, and Pax6 in vTh is apparent at E10.5. Coronal sections of the mouse dTh $(A-E)$ and vTh $(F-L)$. Lhx2, Lhx 9 , and $G b x 2$ are expressed in the lateral part of dTh $(A-C$; arrows). Patterns of $L h x 2$ and $G b x 2$ are indistinguishable, and expression of $L h x 9$ extends further dorsally compared with $L h x 2$ and Gbx2. Ngn2 is expressed only in the ventricular zone and not in the lateral part in which $L h \times 2, L h x 9$, and $G b x 2$ are expressed (D; arrow). Lhx2/9 is mostly localized in BrdU-negative cells at the mantle zone, and only a small number of Lhx2/9-positive cells are BrdU-positive (E; arrowheads). Lhx1, and Isl1 are expressed in the mantle zone of vTh, whereas $L h x 5$ and Pax6 are expressed both in the mantle and ventricular zones $(F-I ;$ arrow $)$. Isl1 is expressed only in BrdU-negative cells $(J)$. The mantle zone is already composed of heterogeneous cell populations for the expression of Lhx1, Isl1, and Pax6 $(K, L)$. Scale bars: $A-D, F-I, 100 \mu \mathrm{m} ; E, J-L, 50 \mu \mathrm{m}$.

ated and many have completed their migration and established a mantle zone within which nuclei will differentiate. Even at this early developmental stage, the expression patterns of the eight genes relative to each other are approximately similar to those seen later.

Thus, thalamic neurons appear to express the same subset of these regulatory genes between E12.5 and P2. Each of these genes is expressed in a unique pattern as early as E10.5, when the first thalamic neurons are generated; thus, they may mark distinct subsets of thalamic neurons beginning around the time they are generated through the time they form nuclei. Based on the expression patterns and known functions of these genes, they are good candidates to act in a combinatorial manner to control the specification of nucleispecific properties of thalamic cells and the differentiation of nuclei. This suggestion is supported by analyses of $G b \times 2$-deficient mice (Miyashita-Lin et al., 1999). Although the mutant exhibits a severe disorganization of dTh, some parts that correspond to VP, dLG, Po, and MG persist. These results are consistent with our finding that Gbx2 is not expressed in VP, dLG, and Po, and only in part of MG. Furthermore, the "sparing" of these nuclei in the mutant suggests that the cell populations that express $G b x 2$ do not significantly change over embryonic development.

The expression patterns observed in dTh do not appear to change between E16.5 and P2. However, at E14.5 and E12.5, a band of cells in rostromedial dTh exhibits a $L h \times 2 / G b \times 2$-high, $L h \times 9 /$ Ngn2-low expression not seen later. One possible explanation for the difference is that this population is still present after E14.5 but is mixed with other populations. This possibility is supported by the fact that neurons of rostromedial dTh nuclei are born later than caudolateral dTh nuclei (Altman and Bayer, 1979; Altman and Bayer, 1988) and may mingle with each other during migration. Another possibility is that these cells express a different combination of genes at E16.5 than at E14.5, similar to the finding that some spinal motor neurons initially express Lhx3 and Lhx4 but later do not (Sharma et al., 1998).

\section{Heterogeneity in gene expression within a nucleus}

Because thalamic nuclei contain multiple types of neurons, regulatory genes might exhibit not only nuclei-specific expression but also differential expression within a nucleus. For example, each subdivision of ZI contains heterogeneous populations of cells that express different neurotransmitters and calcium binding proteins (Kolmac and Mitrofanis, 1998). In the putative ZI at E12.5, our immunostaining for Lhx1/5, Is11, and Pax6 reveals at least four (and possibly 18) different subsets of cells; in rostral ZI, cells only express Isl 1 or Lhx1/5, whereas in caudal ZI, many cells express Isl1 and Lhx1/5. Therefore, the differential expression of Lhx1/5, Is11, and Pax6 may have a role in regulating the differentiation of specific cell types and subdivisions within this nucleus.

Lhx1, Lhx5, and Pax6 may have a similar role within vLG, because it is subdivided by their differential expression. This heterogeneity of gene expression is also evident in the ZLI, which at this stage of development appears to be a migratory stream con- 
taining vLG neurons. Based on the expression of the regulatory genes Dlx1, Arx, Brx1, and Nkx2.2, Kitamura et al. (1997) have suggested that ZLI is composed of two cell groups that give rise to different parts of vLG. Together our findings show that vLG is subdivided into multiple domains based on the differential expression of regulatory genes and that this molecular heterogeneity is already evident while vLG neurons are migrating within the ZLI.

\section{Potential roles in control of TCA axon pathfinding}

Combinations of LIM-HD genes expressed by subsets of motor neurons in vertebrates and Drosophila constitute a "LIM-HD combinatorial code" that dictates their axonal pathfinding (Tsuchida et al., 1994; Sharma et al., 1998; Thor et al., 1999). In addition, the Drosophila LIM-HD gene apterous, the ortholog of $L h \times 2$ and $L h \times 9$, is required for the axonal pathfinding of a subset of interneurons (Lungdren et al., 1995). Similarly, the differential expression of LIM-HD genes in dTh nuclei might regulate TCA pathfinding in a cell-autonomous manner.

Candidate genes regulated by the potential "combinatorial transcription factor code" include Eph receptor tyrosine kinases (Gao et al., 1998; Mackarehtschian et al., 1999; Vanderhaeghen et al., 2000) and cadherins such as Cad6, Cad8, and Cad11, which have matching expression between dTh nuclei and their target cortical areas (Suzuki et al., 1997; Inoue et al., 1998). Interestingly, Lhx2 expression also shows a correlation between dTh and neocortex; the auditory area expresses the highest level of $L h x 2$ in the cortical plate (Nakagawa et al., 1999), the target of MGv axons, the only principal sensory nucleus that highly expresses Lhx2 (present study). The visual and somatosensory areas express lower levels of Lhx2 (Nakagawa et al., 1999), and the principal sensory nuclei that project to them, VP and dLG, do not express Lhx2 (present study). Because $L h x 2$ expression in cortex is established independent of TCAs (Nakagawa et al., 1999), the matching of $L h \times 2$ expression between dTh and cortex may independently regulate the expression of molecules involved in TCA targeting from $\mathrm{MGv}$ to the auditory area.

Our results also suggest a role for these genes in controlling TCA pathfinding through a non-cell-autonomous mechanism. At E12.5, Lhx1, Lhx5, Isl1, and Pax6 are expressed in distinct patterns that mark domains along the TCA pathway through vTh to ventral telencephalon and may influence the expression of guidance molecules. For example, RT expresses RPTPS (Tuttle et al., 1999; present study), which could function as both a ligand and a receptor for axon guidance (Wang and Bixby, 1999), and Slit1 (J. E. Braisted, T. Ringstedt, and D. D. M. O'Leary, unpublished observations), a repulsive axon guidance molecule and a ligand for robo receptors (Brose et al., 1999; Kidd et al., 1999; Li et al., 1999), which are expressed in dTh (Braisted, Ringstedt, and O'Leary, unpublished observations). The perireticular nucleus, which is apposed to the TCA path near the border of vTh and ventral telencephalon (Clemence and Mitrofanis, 1992; Earle and Mitrofanis, 1996), has been proposed to be a guidepost for TCAs (Mitrofanis and Guillery, 1993) (but see Coleman and Mitrofanis, 1999). Although molecular markers defining this nucleus have not been reported for early stages, it appears to coincide with the rostral part of the Isl1-positive, putative RT (present study), and/or ventral telencephalic cells expressing $N k x 2.1$ (Tuttle et al., 1999).

\section{Regionalization of diencephalon into dTh and vTh}

The sets of genes that we show to be expressed in dTh and vTh are distinct from one another and similar to those expressed in dorsal and ventral spinal cord, respectively. This similarity suggests that the expression patterns in thalamus might be established by mechanisms similar to those in spinal cord. In spinal cord, inductive signals from the roof plate and floor plate control neuronal fate along the dorsoventral axis (Tanabe and Jessell, 1996; Lee and Jessell, 1999). Signals from the roof plate, such as TGF $\beta$ family members, are required in dorsal spinal cord for the induction of Lhx2 and $L h x 9$, which define D1A and D1B interneurons, respectively (Liem et al., 1997; Lee and Jessell, 1999; Lee et al., 2000). In ventral spinal cord, distinct classes of motor neurons and ventral interneurons are generated by a graded signaling activity of Shh (Briscoe et al., 1999, 2000). Shh controls these neural fates by establishing different progenitor cell populations defined by their expression of Pax6 and Nkx2.2. Pax6 establishes distinct populations of ventral progenitor cells and controls the identity of motor neurons and V1 and V2 interneurons (Ericson et al., 1997), whereas Nkx2.2 specifies the identity of V3 interneurons at a more ventral location (Briscoe et al., 1999). These genes appear to be essential intermediaries for Shh to regulate the differential expression of LIM-HD proteins, including Lhx1, Lhx3, Lhx4, Lhx5, Isl1, and Isl2.

In diencephalon, Shh is transiently expressed as early as E9.5 in the ZLI, which at this stage is a narrow cell domain interposed between prospective dTh and vTh (Shimamura et al., 1995; Kitamura et al., 1997). Similar to ventral spinal cord, Nkx2.2 and Pax6 are also expressed in progenitor cells in vTh. Shh induces in vitro the expression of Is11 in chick forebrain explants and neuroepithelial cells from rat forebrain (Ericson et al., 1995; Nakagawa et al., 1996). Therefore, ZLI-derived Shh may specify progenitor cell types in vTh to produce different neuronal subtypes, which are determined by the subset of LIM-HD and other transcription factors expressed by these neurons. Interestingly, dTh, which is adjacent to the ZLI, does not express any of the LIM-HD genes induced by Shh and expressed in vTh. Ngn2, which is expressed by progenitor cells of dTh but not vTh, could act to limit the responsiveness of dTh to an Shh-mediated induction of vTh-type LIM-HD genes, which may be a crucial step in regionalization of the diencephalon.

\section{REFERENCES}

Altman J, Bayer SA (1979) Development of the diencephalon in the rat. IV. Quantitative study of the time of origin of neurons and the internuclear chronological gradients in the thalamus. J Comp Neurol 188:455-471.

Altman J, Bayer SA (1988) Development of the rat thalamus. I. Mosaic organization of the thalamic neuroepithelium. J Comp Neurol 275:346-377.

Altman J, Bayer SA (1989a) Development of the rat thalamus. IV. The intermediate lobule of the thalamic neuroepithelium and the time and site of origin and settling pattern of neurons of the ventral nuclear complex. J Comp Neurol 284:534-566.

Altman J, Bayer SA (1989b) Development of the rat thalamus. V. The posterior lobule of the thalamic neuroepithelium and the time and site of origin and settling pattern of neurons of the medial geniculate body. J Comp Neurol 284:567-580.

Altman J, Bayer SA (1989c) Development of the rat thalamus. VI. The posterior lobule of the thalamic neuroepithelium and the time and site of origin and settling pattern of neurons of the lateral geniculate and lateral posterior nuclei. J Comp Neurol 284:581-601.

Angevine Jr JB (1970) Time of neuron origin in the diencephalon of the mouse. An autoradiographic study. J Comp Neurol 139:129-187.

Bertuzzi S, Sheng HZ, Copeland NG, Gilbert DJ, Jenkins NA, Taira M, Dawid IB, Westphal H (1996) Molecular cloning, structure, and chromosomal localization of the mouse LIM/homeobox gene Lhx5. Genomics 36:234-239.

Bertuzzi S, Porter FD, Pitts A, Kumar M, Agulnick A, Wassif C, Westphal H (1999) Characterization of Lhx9, a novel LIM/homeobox gene expressed by the pioneer neurons in the mouse cerebral cortex. Mech Dev 81:193-198. 
Braisted JE, Tuttle R, O’Leary DDM (1999) Thalamocortical axons are influenced by chemorepellent and chemoattractant activities localized to decision points along their path. Dev Biol 208:430-440.

Briscoe J, Sussel L, Serup P, Hartigan-O'Connor D, Jessell TM, Rubenstein JLR, Ericson J (1999) Homeobox gene Nkx2.2 and specification of neuronal identity by graded Sonic hedgehog signalling. Nature 398:622-627.

Briscoe J, Pierani A, Jessell TM, Ericson J (2000) A homeodomain protein code specifies progenitor cell identity and neuronal fate in the ventral neural tube. Cell 101:435-445.

Brose K, Bland KS, Wang KH, Arnott D, Henzel W, Goodman CS, Tessier-Lavigne M, Kidd T (1999) Slit proteins bind Robo receptors and have an evolutionarily conserved role in repulsive axon guidance. Cell 96:795-806.

Bulfone A, Puelles L, Porteus MH, Frohman MA, Martin GR, Rubenstein JLR (1993) Spatially restricted expression of Dlx-1, Dlx-2 (Tes-1), Gbx-2, and Wnt-3 in the embryonic day 12.5 mouse forebrain defines potential transverse and longitudinal segmental boundaries. J Neurosci 13:3155-3172.

Clemence AE, Mitrofanis J (1992) Cytoarchitectonic heterogeneities in the thalamic reticular nucleus of cats and ferrets. J Comp Neurol 322:167-180.

Coleman KA, Mitrofanis J (1999) Does the perireticular thalamic nucleus project to the neocortex? Anat Embryol (Berl) 200:521-531.

Earle KL, Mitrofanis J (1996) Genesis and fate of the perireticular thalamic nucleus during early development. J Comp Neurol 367:246-263.

Ericson J, Muhr J, Placzek M, Lints T, Jessell TM, Edlund T (1995) Sonic hedgehog induces the differentiation of ventral forebrain neurons: a common signal for ventral patterning within the neural tube. Cell 81:747-756

Ericson J, Rashbass P, Schedl A, Brenner-Morton S, Kawakami A, van Heyningen V, Jessell TM, Briscoe J (1997) Pax6 controls progenitor cell identity and neuronal fate in response to graded Shh signaling. Cell 90:169-180.

Figdor MC, Stern CD (1993) Segmental organization of embryonic diencephalon. Nature 363:630-634

Fode C, Gradwohl G, Morin X, Dierich A, LeMeur M, Goridis C, Guillemot $F(1998)$ The bHLH protein NEUROGENIN 2 is a determination factor for epibranchial placode-derived sensory neurons. Neuron 20:483-494.

Fode C, Ma O, Casarosa S, Ang SL, Anderson DJ, Guillemot F (2000) A role for neural determination genes in specifying the dorsoventral identity of telencephalic neurons. Genes Dev 14:67-80.

Franklin KBJ, Paxinos G (1997) The mouse brain in stereotaxic coordinates. San Diego: Academic.

Fujii T, Pichel JG, Taira M, Toyama R, Dawid IB, Westphal H (1994) Expression patterns of the murine LIM class homeobox gene lim1 in the developing brain and excretory system. Dev Dyn 199:73-83.

Gao PP, Yue Y, Zhang JH, Cerretti DP, Levitt P, Zhou R (1998) Regulation of thalamic neurite outgrowth by the Eph ligand ephrin-A5: implications in the development of thalamocortical projections. Proc Natl Acad Sci USA 95:5329-5334.

Gradwohl G, Fode C, Guillemot F (1996) Restricted expression of a novel murine atonal-related bHLH protein in undifferentiated neural precursors. Dev Biol 180:227-241.

Grindley JC, Hargett LK, Hill RE, Ross A, Hogan BL (1997) Disruption of PAX6 function in mice homozygous for the Pax6Sey-1Neu mutation produces abnormalities in the early development and regionalization of diencephalon. Mech Dev 64:111-126.

Hobert I, Westphal I (2000) Functions of LIM-homeobox genes. Trends Genet 16:75-83.

Inoue T, Tanaka T, Suzuki SC, Takeichi M (1998) Cadherin-6 in the developing mouse brain: expression along restricted connection systems and synaptic localization suggest a potential role in neuronal circuitry. Dev Dyn 211:338-351.

Jones EG (1985) The thalamus. New York: Plenum.

Jones EG (1998) A new view of specific and nonspecific thalamocortical connections. Adv Neurol 77:49-71.

Jurata LW, Thomas JB, Pfaff SL (2000) Transcriptional mechanisms in the development of motor control. Curr Opin Neurobiol 10:72-79.

Kaufman MH (1995) The atlas of mouse development. San Diego: Academic.

Kawano H, Fukuda T, Kubo K, Horie M, Uyemura K, Takeuchi K, Osumi N, Eto K, Kawamura K (1999) Pax-6 is required for thalamocortical pathway formation in fetal rats. J Comp Neurol 408:147-160.

Kidd T, Bland KS, Goodman CS (1999) Slit is the midline repellent for the robo receptor in Drosophila. Cell 96:785-794.

Kitamura K, Miura H, Yanazawa M, Miyashita T, Kato K (1997) Expression patterns of Brx1 (Rieg gene), Sonic hedgehog, Nkx2.2, Dlx1 and Arx during zona limitans intrathalamica and embryonic ventral lateral geniculate nuclear formation. Mech Dev 67:83-96.

Kolmac C, Mitrofanis J (1998) Distribution of various neurochemicals within the zona incerta: an immunocytochemical and histochemical study. Anat Embryol (Berl) 199:265-280.
Lee KJ, Jessell TM (1999) The specification of dorsal cell fates in the vertebrate central nervous system. Annu Rev Neurosci 22:261-294.

Lee KJ, Dietrich P, Jessell TM (2000) Genetic ablation reveals that the roof plate is essential for dorsal interneuron specification. Nature 403:734-740.

Li HS, Chen JH, Wu W, Fagaly, T, Zhou L, Yuan W, Dupuis S, Jiang ZH, Nash W, Gick C, Ornitz DM, Wu JY, Rao Y (1999) Vertebrate slit, a secreted ligand for the transmembrane protein roundabout, is a repellent for olfactory bulb axons. Cell 96:807-818.

Liem Jr KF, Tremml G, Jessell TM (1997) A role for the roof plate and its resident TG Fbeta-related proteins in neuronal patterning in the dorsal spinal cord. Cell 91:127-138.

Lin CS, Nicolelis MA, Schneider JS, Chapin JK (1990) A major direct GABAergic pathway from zona incerta to neocortex. Science 248:1553-1556.

Lundgren SE, Callahan CA, Thar S, Thomas JB (1995) Control of neuronal pathway selection by the Drosophila $\mathrm{L} / \mathrm{M}$ homeodomain gene apterous. Development 121:1769-1773.

Ma Q, Fode C, Guillemot F, Anderson DJ (1999) Neurogenin1 and neurogenin2 control two distinct waves of neurogenesis in developing dorsal root ganglia. Genes Dev 13:1717-1728.

Mackarehtschian K, Lau CK, Caras I, McConnell SK (1999) Regional differences in the developing cerebral cortex revealed by ephrin-A5 expression. Cereb Cortex 9:601-610.

Mitrofanis J, Guillery RW (1993) New views of the thalamic reticular nucleus in the adult and the developing brain. Trends Neurosci $16: 240-245$

Miyashita-Lin EM, Hevner R, Wassarman KM, Martinez S, Rubenstein JLR (1999) Early neocortical regionalization in the absence of thalamic innervation. Science 285:906-909.

Mizuno K, Hasegawa K, Katagiri T, Ogimoto M, Ichikawa T, Yakura H (1993) MPTP delta, a putative murine homolog of HPTP delta, is expressed in specialized regions of the brain and in the B-cell lineage. Mol Cell Biol 13:5513-5523.

Nakagawa Y, Kaneko T, Ogura T, Suzuki T, Torii M, Kaibuchi K, Arai K, Nakamura S, Nakafuku M (1996) Roles of cell-autonomous mechanisms for differential expression of region-specific transcription factors in neuroepithelial cells. Development 122:2449-2464.

Nakagawa Y, Johnson JE, O'Leary DDM (1999) Graded and areal expression patterns of regulatory genes and cadherins in embryonic neocortex independent of thalamocortical input. J Neurosci 19:10877-10885.

Nicolelis MA, Chapin JK, Lin RC (1995) Development of direct GABAergic projections from the zona incerta to the somatosensory cortex of the rat. Neuroscience 65:609-631.

Paxinos G, Ashwell KWS, Tork I (1994) Atlas of the developing rat nervous system. San Diego: Academic.

Puelles L (1995) A segmental morphological paradigm for understanding vertebrate forebrains. Brain Behav Evol 46:319-337.

Puelles L, Rubenstein JLR (1993) Expression patterns of homeobox and other putative regulatory genes in the embryonic mouse forebrain suggest a neuromeric organization. Trends Neurosci 16:472-479.

Retaux S, Rogard M, Bach I, Failli V, Besson MJ (1999) Lhx9: a novel LIM-homeodomain gene expressed in the developing forebrain. J Neurosci 19:783-793.

Rubenstein JLR, Shimamura K, Martinez S, Puelles L (1998) Regionalization of the prosencephalic neural plate. Annu Rev Neurosci 21:445-477.

Sharma K, Sheng HZ, Lettieri K, Li H, Karavanov A, Potter S, Westphal H, Pfaff SL (1998) LIM homeodomain factors Lhx3 and Lhx4 assign subtype identities for motor neurons. Cell 95:817-828.

Sheng HZ, Bertuzzi S, Chiang C, Shawlot W, Taira M, Dawid I, Westphal $\mathrm{H}$ (1997) Expression of murine Lhx5 suggests a role in specifying the forebrain. Dev Dyn 208:266-277.

Shimamura K, Hartigan DJ, Martinez S, Puelles L, Rubenstein JLR (1995) Longitudinal organization of the anterior neural plate and neural tube. Development 121:3923-3933.

Sommer L, Ma Q, Anderson DJ (1996) neurogenins, a novel family of atonal-related bHLH transcription factors, are putative mammalian neuronal determination genes that reveal progenitor cell heterogeneity in the developing CNS and PNS. Mol Cell Neurosci 8:221-241.

Sommer L, Rao M, Anderson DJ (1997) RPTP delta and the novel protein tyrosine phosphatase RPTP psi are expressed in restricted regions of the developing central nervous system. Dev Dyn 208:48-61.

Stoykova A, Gruss P (1994) Roles of Pax-genes in developing and adult brain as suggested by expression patterns. J Neurosci 14:1395-1412.

Stoykova A, Fritsch R, Walther C, Gruss P (1996) Forebrain patterning defects in Small eye mutant mice. Development 122:3453-3465.

Suzuki SC, Inoue T, Kimura Y, Tanaka T, Takeichi M (1997) Neuronal circuits are subdivided by differential expression of type-II classic cadherins in postnatal mouse brains. Mol Cell Neurosci 9:433-447.

Tanabe Y, Jessell TM (1996) Diversity and pattern in the developing spinal cord. Science 274:1115-1123.

Thor S, Ericson J, Brannstrom T, Edlund T (1991) The homeodomain 
LIM protein Isl-1 is expressed in subsets of neurons and endocrine cells in the adult rat. Neuron 7:881-889.

Thor S, Andersson SG, Tomlinson A, Thomas JB (1999) A LIMhomeodomain combinatorial code for motor-neuron pathway selection. Nature 397:76-80.

Tsuchida T, Ensini M, Morton SB, Baldassare M, Edlund T, Jessell TM, Pfaff SL (1994) Topographic organization of embryonic motor neurons defined by expression of LIM homeobox genes. Cell 79:957-970.

Tuttle R, Nakagawa Y, Johnson JE, O'Leary DDM (1999) Defects in thalamocortical axon pathfinding correlate with altered cell domains in Mash-1-deficient mice. Development 126:1903-1916.

Vanderhaeghen P, Lu Q, Prakash N, Frisen J, Walsh CA, Frostig RD,
Flanagan JG (2000) A mapping label required for normal scale of body representation in the cortex. Nat Neurosci 3:358-365.

Walther C, Gruss P (1991) Pax-6, a murine paired box gene, is expressed in the developing CNS. Development 113:1435-1449.

Wang J, Bixby JL (1999) Receptor tyrosine phosphatase-delta is a homophilic, neurite-promoting cell adhesion molecule for CNS neurons. Mol Cell Neurosci 14:370-384.

Warren N, Price DJ (1997) Roles of Pax-6 in murine diencephalic development. Development 124:1573-1582.

Wong-Riley M (1979) Changes in the visual system of monocularly sutured or enucleated cats demonstrable with cytochrome oxidase histochemistry. Brain Res 171:11-28. 